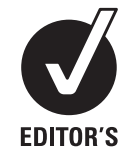

CHOICE

\title{
Bladder cancer risk in painters: a meta-analysis
}

\author{
Neela Guha, ${ }^{1}$ Nelson Kyle Steenland, ${ }^{2}$ Franco Merletti, ${ }^{3}$ Andrea Altieri, ${ }^{4}$ \\ Vincent Cogliano, ${ }^{1}$ Kurt Straif ${ }^{1}$
}

\begin{abstract}
See Editorial, p 505
- Additional tables are published online only. To view these files please visit the journal online (http://oem.bmj. com)

${ }^{1}$ Section of IARC Monographs, International Agency for Research on Cancer, Lyon cedex, France

${ }^{2}$ Rollins School of Public Health, Department of Environmental and Occupational Health, Emory University, Atlanta, Georgia, USA

${ }^{3}$ Unit of Cancer Epidemiology, Department of Biomedical Sciences and Human Oncology, University of Turin, Turin, Italy ${ }^{4}$ Emerging Risks Unit, European Food Safety Authority, Parma, Italy
\end{abstract}

\section{Correspondence to}

Dr Neela Guha, Section of IARC Monographs, 150 cours Albert Thomas, 69372 Lyon Cedex 08, France; guhan@iarc.fr

Accepted 13 October 2009

\section{ABSTRACT}

The International Agency for Research on Cancer has classified occupational exposure as a painter as 'carcinogenic to humans', largely based on increased risks of bladder and lung cancer. A meta-analysis, including more than 2900 incident cases or deaths from bladder cancer among painters reported in 41 cohort $(n=2)$, record linkage $(n=9)$ and case-control $(n=30)$ studies, was conducted to quantitatively compare the results of the different study designs and the potential confounding effect of smoking as well as other occupational exposures. The summary relative risk (meta-RR, random effects) for bladder cancer in painters was 1.25 (95\% Cl 1.16 to $1.34 ; 41$ studies) overall and 1.28 (95\% Cl 1.15 to 1.43; 27 studies) when including only smoking adjusted risk estimates. The elevated risk persisted when restricted to studies that adjusted for other occupational exposures (meta-RR 1.27; 95\% Cl 0.99 to $1.63 ; 4$ studies). The results remained robust when stratified by study design, gender and study location. Furthermore, exposure-response analyses suggested that the risk increased with duration of employment. There was no evidence of publication bias. Taken together, these results support the conclusion that occupational exposures in painters are causally associated with the risk of bladder cancer.

\section{INTRODUCTION}

The International Agency for Research on Cancer (IARC) estimated that bladder cancer is the 9th most common cancer diagnosis worldwide, with more than 330000 new cases each year and more than 130000 deaths per year. ${ }^{1}$ Cigarette smoking is the most important risk factor for bladder cancer, accounting for approximately $66 \%$ of new cases in men and $30 \%$ of the cases in women in industrialised populations. ${ }^{23}$ Much of this risk is likely due to the presence of aromatic amines in cigarette smoke, such as 2-naphthylamine, 4-aminobiphenyl and 4-chloro-ortho-toluidine. ${ }^{4}$ An increased risk of bladder cancer has also been reported among workers in certain industries, such as rubber manufacture and painting, ${ }^{5}$ that also involve exposure to the same aromatic amines found in cigarette smoke (eg, 2-naphthylamine, 4-aminobiphenyl). ${ }^{4} 6$ The IARC has classified occupational exposure as a painter as 'carcinogenic to humans' (group 1). 578 Although the previous IARC group 1 evaluation was largely based on an increased risk of lung cancer in painters, in 2007 the IARC newly identified that there was sufficient evidence that occupational exposure as a painter causes bladder cancer.

Cohort and record linkage studies demonstrating a relatively consistent increased incidence and mortality from bladder cancer among painters ${ }^{9-24}$

\section{What this paper adds}

- The International Agency for Research on Cancer has classified occupational exposure as a painter as 'carcinogenic to humans', largely based on increased risks of lung and bladder cancer.

- This meta-analysis quantitatively summarises all of the literature to date reporting on the association between occupational exposure as a painter and bladder cancer.

- These results support the conclusion that occupational exposures in painters are causally associated with the risk of bladder cancer, after controlling for smoking, other occupational exposures, gender, study design and study location.

- The robustness of the results is also indicated by the presence of a duration-response relationship, with higher RRs seen for exposure occurring for $>10$ years (meta-RR 1.81) when compared to $<10$ years of exposure (meta-RR 1.41) (the reference category was no exposure).

- It is important for cancer control and prevention to design studies with more specific exposure assessment that quantifies individual agents or classes of agents to identify the underlying carcinogenic agents encountered in painting.

have supported the IARC group 1 classification, although potential confounding by tobacco smoking could not be ruled out in several of these studies. (Here we refer to record linkage studies as a subset of cohort studies where two databases are linked, such as a cohort of painters derived from census data and national mortality data, with only minimum demographic information available for the cohort.) Case-control studies have also shown that occupational exposure as a painter is a risk factor for bladder cancer, ${ }^{25-30}$ albeit somewhat less consistently, ${ }^{31-40}$ and the increased risk persisted after adjusting for the potential confounding by smoking. ${ }^{41-67}$

To assess the risk of bladder cancer associated with occupational exposure as a painter, we conducted a meta-analysis of cohort, record linkage (see online tables 1 and 2) and case-control studies (see online tables 3 and 4) to quantitatively compare the results of the different study designs, the potential confounding effect of smoking, as well as other analyses to support the causal association. A thorough discussion of the individual studies included in the meta-analysis is not presented here but is summarised in the IARC monographs. ${ }^{5}$ The new 
studies published after the IARC monograph (published in 1989) are summarised in online tables 2 and 4 , while the older studies are summarised in online tables 1 and 3 .

\section{METHODS \\ Selection criteria}

All epidemiological studies included in the previous IARC monographs were considered. ${ }^{5}$ Further, articles in any language describing bladder cancer in painters referenced in or published after the previous IARC monograph (published in 1989) ${ }^{5}$ were searched for in PubMed until 24 August 2009 using the search terms '(paint* $[\mathrm{tw}]$ OR varnish*[tw] OR lacquer*[tw]) AND (cancer OR neoplasms[mh]) AND (case-control study[mesh] OR cohort study[mesh] OR meta-analysis[mh] OR review[pt] OR risk factors[mh] OR neoplasms/epidemiology OR neoplasms/etiology OR neoplasms/CI OR occupational diseases/etiology OR occupational diseases/epidemiology OR occupational diseases/CI OR occupational diseases/MO OR occupational exposure/adverse effects $\mathrm{OR}$ death certificates [mh] OR epidemiologic methods[mh]) AND bladder'. Eighty six publications were identified after restricting to studies in humans. From the PubMed search, 47 studies were excluded because they were either not an epidemiological study, did not include original data (review articles), did not assess occupation as a painter, overlapped with another population already included in the meta-analysis, or bladder cancer was not the outcome. The reference lists of pertinent articles were also reviewed to capture relevant publications that may not have been identified with the search criteria.

The definition of painter varied between studies and often included those in other occupations exposed to paints such as plasterers, glaziers, wallpaper hangers, artists, decorators, French polishers and aerographers (see online table 5). It is likely that these workers together with paper-hangers have the same job environment as painters or may also paint, and therefore this category was also considered as 'painters'. 68

To be included in this meta-analysis, studies had to report estimates of the relative risk ( $R R, O R, S I R, S M R)$ with corresponding $95 \%$ CIs for ever versus never occupation as a painter or provide enough information that allowed for their computation. For studies that did not report the ever versus never painter category, the risk estimates and 95\% CIs for these categories were estimated (see Statistical analysis section). For studies that reported only point estimates without corresponding CIs, $\mathrm{p}$ values or standard errors, or did not report the distribution of data to allow for computation of relative risks and CIs, conservative assumptions were made to estimate relative risks and 95\% CI from the data provided on a study-bystudy basis. These conservative assumptions underestimated the relative risk (towards the null) and overestimated the width of the CI (ie, by doubling the variance to approximate a $95 \% \mathrm{CI}$ adjusted for multiple factors). Studies were excluded if estimation was impossible. Square brackets indicate the relative risks and $95 \%$ CIs calculated by the authors (see online tables 1-4) For studies with overlapping populations, only the publication with the most complete study population was included (see online tables 1-4). In total, 11 cohort and record linkage studies and 30 case-control studies were included in the meta-analysis.

\section{Data abstraction}

All articles were assessed independently by three reviewers (AA, FM, NKS) who extracted data that included authors, publication date, country of origin, characteristics of the study population including gender and any details on the definition of painters, incidence versus mortality, bladder cancer histology, observed and expected cancer cases (for cohort and proportionate mortality studies), number of exposed cases and controls (for case-control studies), yes/no adjustment for smoking or other occupational carcinogens, relative risks with corresponding $95 \%$ CIs and results on exposure-response (see online tables 1-4). If adjusted and unadjusted results were reported, the most valid point estimate (ie, adjusted for smoking and other variables) was abstracted. Any discrepancies in data collection were resolved by two other reviewers (NG, KS).

Summary statistics calculated for inclusion in the meta-analysis For cohort and record linkage studies, risk estimates (standardised incidence ratios (SIR) or standardised mortality ratios $(\mathrm{SMR})$ ) were computed by dividing the observed number of cases by the expected number, based on an external reference population. The corresponding $95 \%$ CIs were estimated using the PAMCOMP program. ${ }^{69}$ If only subgroup results (eg, by gender, race or duration of exposure) were reported, fixed effects models were used to combine stratum specific data into one summary estimate (see online tables 1-4).

Subgroup analyses were conducted by further restricting to studies with stronger methodologies, such as those studies that adjusted for smoking, other occupational risk factors or population-based case-control studies that adjusted for smoking. Only two of the cohort and record linkage studies provided information on smoking status.

To allow for inclusion in the meta-analysis, 95\% CIs were calculated if they were not presented in the original paper. If a $90 \%$ CI was presented and if the upper (UL) and lower limit (LL) were proportionally symmetric around the risk ratio (for RR and $\mathrm{OR}$; ie, if $\mathrm{UL} / \mathrm{RR}=\mathrm{RR} / \mathrm{LL})$, an estimate of the SE was calculated by $\mathrm{SE}=(\ln \mathrm{UL}-\ln \mathrm{LL} / 3.29)$, where $3.29=2 \times 1.645$ for $90 \%$ CIs. If only a p value for the null hypothesis was presented, then a 'test-based' $\mathrm{SE}$ was estimated using $\mathrm{SE}=(\ln \mathrm{RR}) / Z_{\mathrm{p}}$, where $Z_{p}$ is the value of the standard-normal test statistic corresponding to the $\mathrm{p}$ value using a two-tailed test. The UL and $\mathrm{LL}$ of the $95 \% \mathrm{CI}$ were estimated by $\exp [\ln (\mathrm{RR}) \pm 1.96(\mathrm{SE})]$, where $Z_{p}=1.96$ if $p=0.05$ using a two-tailed test. ${ }^{70} \mathrm{~A} 95 \% \mathrm{CI}$ corresponding to an unadjusted RR was used in the meta-analysis if a paper did not present enough data to allow for estimation of the adjusted CI.

\section{Statistical analysis}

For cohort and record linkage studies, incidence and mortality data were compared. Because cancer incidence data are often more accurate than mortality data, SIRs were used in the combined analyses instead of SMRs whenever both were presented. Assuming that the different effect estimates (eg, SMR, SIR, RR, OR) represent the relative risk, the data were combined for all of the cohort, record linkage and case-control studies. Separate meta-analyses were also done by study design.

Many of the cohort and record linkage studies used an external reference population to calculate the expected cases. When the external reference rates that are used to calculate the expected cases are usually assumed to be known without error, an estimate of the exposure coefficient could be obtained with a weighted linear regression of the natural log of the adjusted SMR on exposure. ${ }^{71}$ The risk estimates from nested casecontrol studies were included with the analysis of cohort studies because, essentially, this design can represent a more efficient way to analyse cohort studies and does not have the problems associated with control selection in a case-control study. Summary odds ratios (meta-OR) were obtained separately from 
the meta-analysis of case-control studies. Subgroup analyses were performed stratified by gender, study region, study design, types of adjustment and duration of employment.

The $\mathrm{I}^{2}$ statistic quantified the extent of inconsistency among the studies. ${ }^{72} \mathrm{I}^{2}$ values of $25 \%-50 \%$ indicate moderate inconsistency, while values larger than 50\% reflect large inconsistencies among studies. The $\mathrm{I}^{2}$ values were presented instead of the Cochran's $\mathrm{Q}$ statistic because the $\mathrm{Q}$ statistic only indicates the presence or absence of heterogeneity but does not quantify the extent. ${ }^{73}$ Both random and fixed effect models, with weights equal to the inverse of the variance, were used to calculate a summary risk estimate. ${ }^{74}$ Results from random effects models, which account for heterogeneity among studies, are presented.

Influence analyses were conducted by dropping one study at a time and examining its influence on the summary effect estimates. Forest plots were used to graphically display the data. ${ }^{75}$ In the forest plot, the risk estimate for each study is represented by a black diamond, the horizontal line shows the corresponding 95\% CI and a dashed line marks the summary estimate, while the vertical solid line represents the null result. Publication bias was visually assessed using funnel plots. ${ }^{76}$ All statistical analyses were performed by using STATA version 10.0, employing the 'metan' command for the meta-analyses. ${ }^{77}$

\section{RESULTS}

This paper summarises 41 studies published since 1958 assessing the relationship between occupation as a painter and risk of bladder cancer (see online tables 1-4). The estimates of the relative risk ranged from 0.42 to 3.10 , with 37 studies reporting a relative risk above 1.0. The combined analysis of 11 cohort and record linkage studies (meta-RR 1.21; 95\% CI 1.10 to 1.34 ; $\mathrm{I}^{2}=40.1 \%, \mathrm{p}=0.08$ ) and 30 case-control studies (meta-OR 1.29; $95 \%$ CI 1.17 to $1.42 ; \mathrm{I}^{2}=0.8 \%, \mathrm{p}=0.45$ ), including more than 2900 incident cases/deaths from bladder cancer among painters, demonstrated a significantly increased risk overall in persons who had ever reported occupation as a painter (meta-RR 1.25; $95 \%$ CI 1.16 to $1.34 ; \mathrm{I}^{2}=23.5 \%, \mathrm{p}=0.09$ ) (figure 1 ). An influence analysis showed that dropping individual studies did not significantly alter the results (data not shown). Restricting to cohort and record linkage studies and stratifying by the type of data (incidence or mortality) showed that the meta-RRs were consistent in showing an increased risk, with the meta-RR for the mortality data (meta-RR 1.25; 95\% CI 1.13 to 1.39 ; 7 studies) being slightly higher than for the incidence data (metaRR 1.12; 95\% CI 1.00 to 1.26 ; 4 studies).

Risks were higher in female painters (meta-RR 1.55; 95\% CI 1.08 to 2.23 ) than in males (meta-RR $1.24 ; 95 \%$ CI 1.15 to 1.34 ). It is notable that although there were only four studies among
Figure 1 Meta-analysis of all studies assessing bladder cancer among persons with occupation as a painter, stratified by study design. If only subgroup results (eg, by gender, race or duration of exposure) were reported, fixed effects models (FEs) were used to combine stratum specific data into one summary estimate.

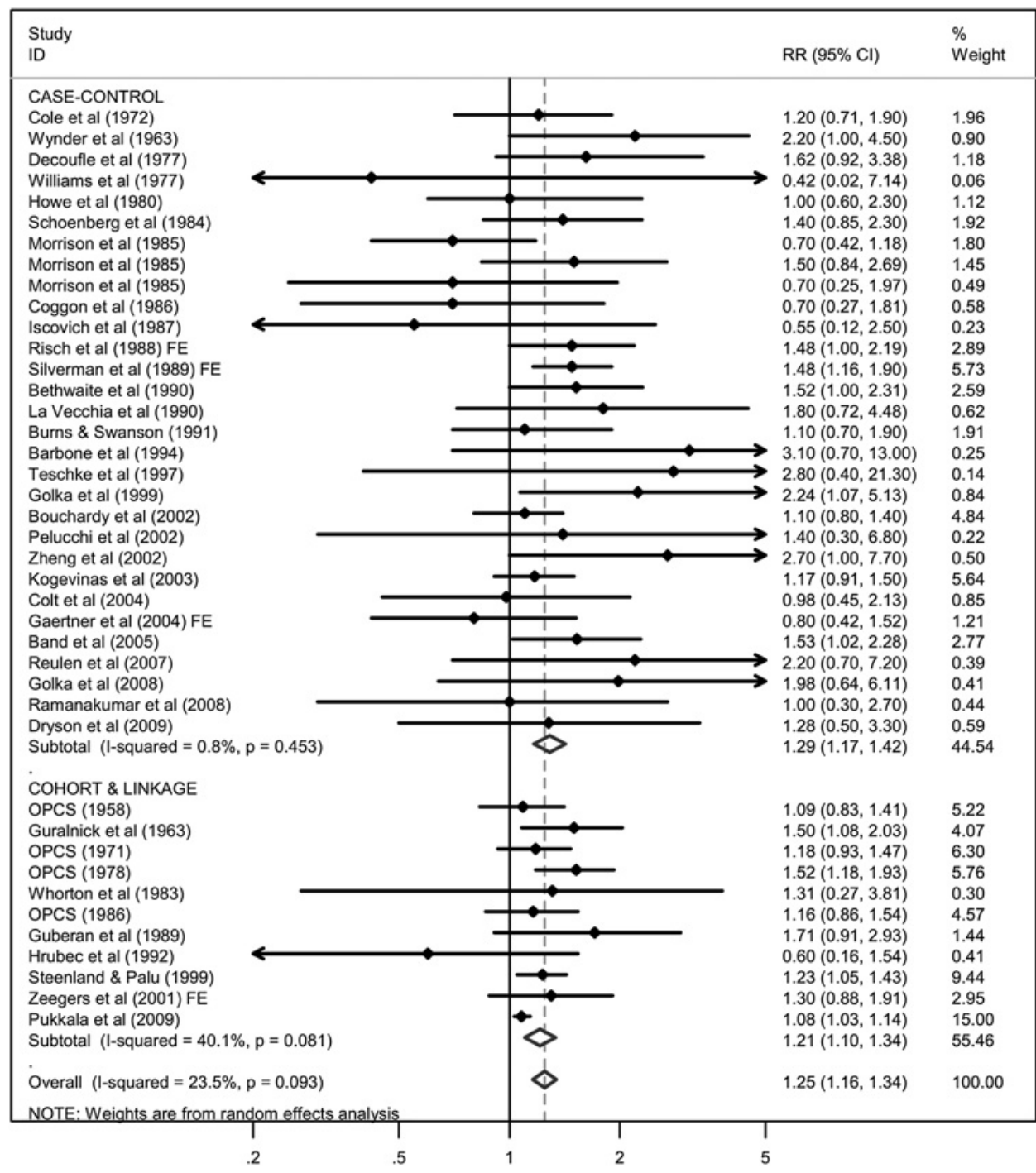

Relative Risk Estimate 
female painters, ${ }^{19} 374557$ the meta-RR was statistically significant. Stratification by study region showed that risks were elevated in Oceania (meta-RR 1.48; 95\% CI 1.01 to 2.17 ; $\mathrm{I}^{2}=0 \%$, $\mathrm{p}=0.74$ ), North America (meta-RR 1.32; 95\% CI 1.20 to 1.46; $\mathrm{I}^{2}=0 \%, \mathrm{p}=0.73$ ) and Europe (meta-RR $1.19 ; 95 \%$ CI 1.08 to 1.32 ; $\mathrm{I}^{2}=30.8 \%, \mathrm{p}=0.11$.

Additional analyses were performed to examine the summary risk estimates when restricted to population-based case-control studies or studies with stronger analytic methods (adjusting for smoking or other occupational exposures). Restricting to studies that adjusted for smoking (meta-OR 1.28; 95\% CI 1.15 to 1.43 ; $\mathrm{I}^{2}=0.7 \%, \mathrm{p}=0.45$ ), population-based case-control studies that adjusted for smoking (meta-OR 1.26; 95\% CI 1.10 to 1.45 ; $\mathrm{I}^{2}=12 \%, \mathrm{p}=0.31$ ) or studies that adjusted for other occupational exposures as well as smoking (meta-RR 1.27; 95\% CI 0.99 to $1.63 ; \mathrm{I}^{2}=0.1 \%, \mathrm{p}=0.39$ ) did not significantly change the results from the overall estimate. Only two cohort studies reported smoking adjusted results ${ }^{10} 78$ with a meta-RR of $1.07(95 \% \mathrm{CI}$ 0.55 to $\left.2.07 ; \mathrm{I}^{2}=37.6 \%, \mathrm{p}=0.21\right)$. One of the two cohort studies was based on only four exposed cases (SMR 0.60; 95\% CI 0.16 to 1.54$),{ }^{78}$ while a second study was based on 47 exposed cases [RR 1.30; 95\% CI 0.88 to 1.91], ${ }^{10}$ with higher risks in the medium and high exposure categories. Analysis by duration of exposure $^{4154566279}$ showed that those exposed for $>10$ years (meta-RR 1.81; 95\% CI 1.20 to $2.75 ; \mathrm{I}^{2}=9.1 \%, \mathrm{p}=0.36$ ) had a higher risk than those exposed for $<10$ years (meta-RR 1.41; $95 \%$ CI 1.00 to $2.01 ; \mathrm{I}^{2}=0 \%, \mathrm{p}=0.92$ ) (reference category was 0 years exposure).

There appeared to be no evidence of publication bias overall or among the case-control studies, as assessed by visual inspection of the funnel plot (figure 2). The meta-OR was higher in the eight studies using hospital-based controls (meta-OR 1.57; 95\% CI 1.18 to $2.08 ; \mathrm{I}^{2}=0 \%, \mathrm{p}=0.71$ ) than in the 22 studies using population-based controls (meta-OR 1.25; 95\% CI 1.12 to 1.40 ; $\mathrm{I}^{2}=7.1 \%, \mathrm{p}=0.37$ ), although the hospital-based studies were less heterogeneous.

\section{DISCUSSION}

A number of studies demonstrating an increased risk of bladder cancer in painters have supported the IARC classification that occupation as a painter is 'carcinogenic to humans' (group 1). 58 This meta-analysis lends support to the IARC group 1 classification by demonstrating a $25 \%$ increased risk of bladder cancer in painters after adjusting for smoking (meta-RR $1.25 ; 95 \% \mathrm{CI}$ 1.16 to $1.34 ; \mathrm{I}^{2}=23.5 \%, \mathrm{p}=0.09$ ). This association did not change significantly when restricting to population-based case-control studies or studies that adjusted for smoking and other potentially confounding occupational exposures. Furthermore, exposure-response analyses suggested that the risk increased with duration of employment. Although paint composition or the painting environment could have differed by major geographical region, the results did not vary much when stratified by regions that were represented by more than one study (North America, Europe, Oceania).

It is important to note that the interpretation of a meta-SMR (or meta-SIR), for the cohort and record linkage studies, is difficult because different reference populations are used in each study for the calculation of expected cases or deaths. ${ }^{70}$ Although the cohort studies of painters could assess possibly higher exposures from longer periods of follow-up, exposure assessment in many of the record linkage studies was often crude: occupation as a painter was usually assessed at a single time point in a census and then linked to death or cancer registries. Although there can be relatively poor correspondence between occupation recorded on death certificates and in census records ${ }^{12} 13202180$ and there is a chance of false positive results due to multiple testing of occupations in record linkage studies, the SMRs were very consistent between individual studies, generally ranging between 1.08 and 1.71. This also suggested that the significant results were not likely due to chance. Thus the approach to combine the cohort and record linkage study SMRs for calculating a meta-SMR seemed to be justified.

In case-control studies, painters may only form a small proportion of the study population, but the full occupational history and additional information on lifestyle factors allowed several studies to adjust for tobacco smoking and some for other occupational carcinogens. An increased bladder cancer risk associated with painting was consistently demonstrated in the case-control studies, suggesting that occupation as a painter is a risk factor for bladder cancer. Although it was not included in
Figure 2 Funnel plot to assess publication bias in case-control studies of bladder cancer among persons with occupation as a painter.
Begg's funnel plot with pseudo 95\% confidence limits

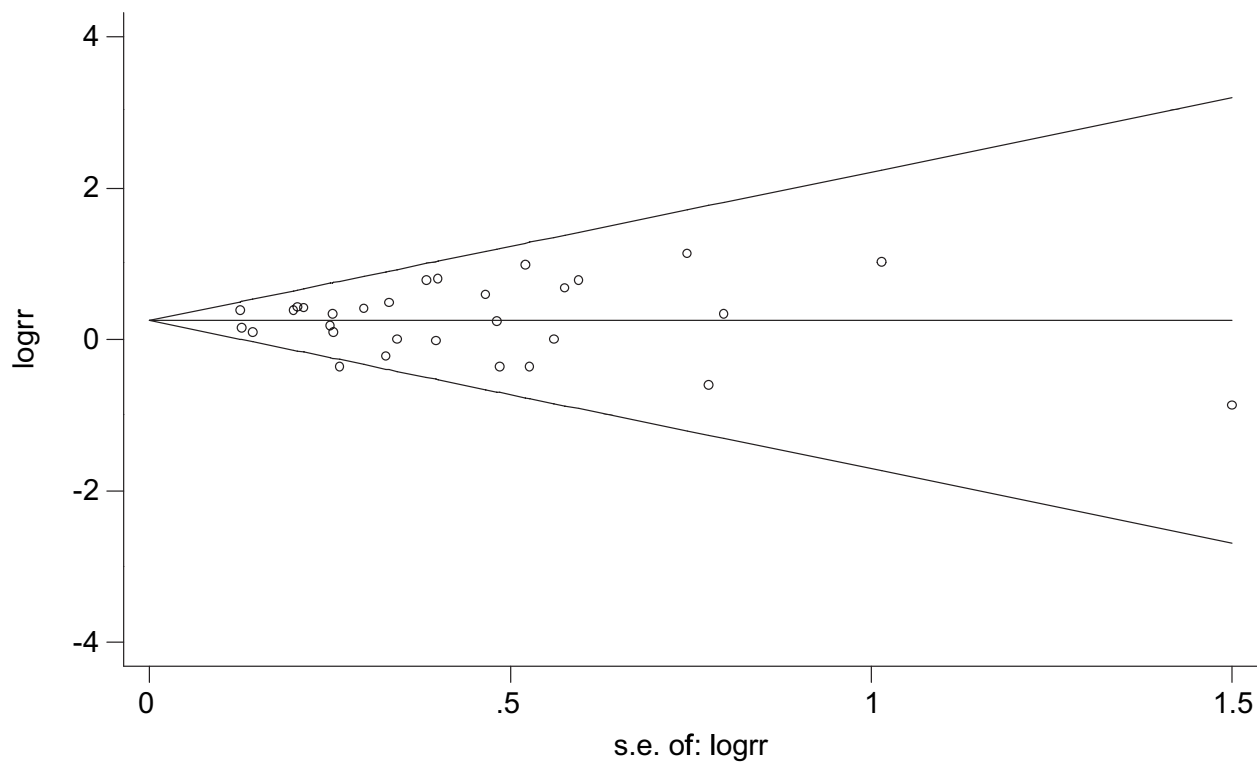


the meta-analysis because artistic painters may have different exposures than those occupationally exposed in the construction or automobile industry, one case-control study also showed an increased risk of bladder cancer in artistic painters. ${ }^{52}$ Populationbased case-control studies may be less subject to selection biases than hospital-based case-control studies ${ }^{70}$ because there is generally no concern about the appropriate source population. However, if response rates are low in population controls, this could result in a lack of comparability with cases and therefore studies could be prone to selection biases. A subanalysis comparing the meta-OR of hospital-based and population-based case-control studies showed that the risks were higher when using hospital-based controls.

Smoking adjusted risk estimates were available for 25 of the 30 case-control studies and in only two of the 11 cohort and record linkage studies. Zeegers et al ${ }^{10}$ demonstrated that the risk for bladder cancer in painters was higher in current smokers (RR 2.22 ; $95 \%$ CI 1.15 to $4.29 ; 32$ exposed cases) than in never smokers (RR $1.35 ; 95 \%$ CI 0.26 to $7.12 ; 2$ exposed cases). The robustness of the summary risk estimates after adjusting for tobacco use, suggest that residual confounding by tobacco use is unlikely and that occupational exposure as a painter is independently associated with the risk of bladder cancer.

The meta-RR restricted to women (meta-RR 1.55; 4 studies) 19374557 was higher than the meta-RR restricted to men (meta-RR 1.24; 34 studies), although female painters may not actually have a higher risk of bladder cancer compared to male painters. The relative risk in women may appear higher because they have a lower background bladder cancer risk than men. (Since there was no overlap in the data included in the metaregressions of males and females separately, we evaluated the statistical significance by calculating the ratio of the meta-RRs, along with a corresponding $95 \% \mathrm{CI}$ and a p value if including the null hypothesis of 1 . In this case, RR1/RR2=1.45, 95\% CI 0.85 to $1.80, \mathrm{p}=0.26$.)

The robustness of the results is also indicated by the presence of a duration-response relationship, with higher RRs seen for exposure occurring for $>10$ years (meta-RR 1.81) when compared to $<10$ years of exposure (meta-RR 1.41), respectively (the reference category was no exposure).

The specific agents causing the increased risk of bladder cancer in painters have not been identified. Very few studies reported results for specific suspected causative agents. A Canadian case-control study ${ }^{59}$ suggested increased risks of bladder cancer in painters with exposure to metal coatings, wood varnishes or stains. These products also contain solvents, fillers and pigments and usually entail other exposure scenarios such as sanding and other surface preparation. To permit identification of specific causative agents encountered in the painting environment, future studies assessing cancer risks in painters should present risk estimates associated with individual components in paint.

\section{CONCLUSION}

The interpretation of epidemiological studies of bladder cancer in painters is complicated by the wide variety of chemical mixtures, whose compositions change over time, and the great variability and complexity of painting environments. Although there was not enough information in the studies provided to assess the association of bladder cancer with specific chemical agents encountered in painting, the robustness of the risk estimates in the subgroup analyses (by gender, region, study design, controlling for smoking and other occupational exposures) and the stronger associations seen in specific subgroups (by duration of exposure) support the conclusion that occupational exposures in painters are causally associated with the risk of bladder cancer. Because several million people are employed as painters worldwide, even a modest increase in the relative risk is remarkable. It is important for cancer control and prevention to design studies with more specific exposure assessment that quantifies individual agents or classes of agents to identify the underlying carcinogenic agents encountered in painting.

Acknowledgements The authors thank Mrs Dorothy Russell and Ms Anne-Sophie Hameau for technical assistance.

Competing interests None.

Contributors All authors have read and contributed to the article.

Provenance and peer review Not commissioned; externally peer reviewed.

\section{REFERENCES}

1. IARC. World cancer report. In: Stewart B, Kleihues P, eds. Lyon, France: IARC Press, 2003.

2. Brennan $\mathbf{P}$, Bogillot 0 , Cordier $\mathbf{S}$, et al. Cigarette smoking and bladder cancer in men: a pooled analysis of 11 case-control studies. Int J Cancer 2000;86:289-94.

3. Brennan $\mathbf{P}$, Bogillot 0 , Greiser $E$, et al. The contribution of cigarette smoking to bladder cancer in women (pooled European data). Cancer Causes Control 2001; 12:411-17

4. IARC. World Cancer Report 2008. In: Boyle P, Levin B, eds. Lyon: International Agency for Research on Cancer, 2008.

5. IARC. Occupational exposures in paint manufacture and painting. 47, 329-442. Lyon: IARC Monographs on the Evaluation of the Carcinogenic Risks to Human. International Agency for Research on Cancer, 1989.

6. Siemiatycki J, Richardson L, Straif K, et al. Listing occupational carcinogens. Environ Health Perspect 2004;112:1447-59.

7. Straif K, Baan R, Grosse $Y$, et al. Carcinogenicity of shift-work, painting, and firefighting. Lancet Oncol 2007;8:1065-6.

8. IARC. Shift-work, Painting and Fire-fighting. IARC Monogr Eval Carcinog Risks Hum. In press.

9. Gubéran $\mathbf{E}$, Usel M, Raymond L, et al. Disability, mortality, and incidence of cancer among Geneva painters and electricians: a historical prospective study. $\mathrm{Br} \mathrm{J}$ Ind Med 1989;46:16-23.

10. Zeegers MP, Swaen GM, Kant I, et al. Occupational risk factors for male bladder cancer: results from a population based case cohort study in the Netherlands. Occup Environ Med 2001;58:590-6.

11. OPCS. Occupational Mortality 1979-80, 1982-1983, Great Britain, Decennial Supplement. Office of Population Censuses and Surveys, ed. London: 1986.

12. OPCS. Occupational mortality 1970-1972, England and Wales, Decennial Supplement. Majesty's Stationery Office. Office of Population Censuses and Surveys, ed. London: 1979

13. OPCS. The Registrar General's Decennial Supplement, England and Wales 1961 Occupational mortality tables. Majesty's Stationery Office. Office of Population Censuses and Surveys, ed. London: 1972.

14. OPCS. The Registrar General's decennial supplement, England and Wales 1951 Occupational mortality. Part II, Vol. 2, Tables, Majesty's Stationery Office. Office of Population Censuses and Surveys, ed. London: 1958.

15. Olsen JH, Jensen OM. Occupation and risk of cancer in Denmark. An analysis of 93,810 cancer cases, 1970-1979. Scand J Work Environ Health 1987;13(Suppl 1):1-91.

16. Malker HS, McLaughlin JK, Silverman DT, et al. Occupational risks for bladder cancer among men in Sweden. Cancer Res 1987:47:6763-6.

17. Skov T, Weiner J, Pukkala E, et al. Risk for cancer of the pharynx and oral cavity among male painters in the Nordic countries. Arch Environ Health 1993:48:176-80.

18. Brown LM, Moradi T, Gridley G, et al. Exposures in the painting trades and paint manufacturing industry and risk of cancer among men and women in Sweden. J Occup Environ Med 2002;44:258-64.

19. Pukkala E. Occupation and cancer - follow-up of 15 million people in five Nordic Countries. Acta Oncol 2009;48:646-790.

20. Guralnick L. Mortality by Occupation Level and Cause of Death Among Men 20 to 64 Years of Age: United States, 1950. In: Guralnick L, ed. Washington DC, USA: US Department of Health, Education and Welfare, 1963.

21. Enterline PE, McKiever MF. Differential mortality from lung cancer by occupation. $\mathrm{J}$ Occup Med 1963;5:283-90.

22. Whorton MD, Schulman J, Larson SR, et al. Feasibility of identifying high-risk occupations through tumor registries. J Occup Med 1983;657-60.

23. Matanoski GM, Stockwell HG, Diamond EL, et al. A cohort mortality study of painters and allied tradesmen. Scand J Work Environ Health 1986;12:16-21.

24. Steenland K, Palu S. Cohort mortality study of 57,000 painters and other union members: a 15 year update. Occup Environ Med 1999;56:315-21.

25. Myslak ZW, Bolt HM, Brockmann W. Tumors of the urinary bladder in painters: a case-control study. Am J Ind Med 1991;19:705-13.

26. Bouchardy C, Schuler G, Minder C, et al. Cancer risk by occupation and socioeconomic group among men-a study by the Association of Swiss Cancer Registries. Scand J Work Environ Health 2002;28:1-88. 
27. Wynder EL, Onderdonk J, Mantel N. An epidemiological investigation of cancer of the bladder. Cancer 1963;16:1388-407.

28. Howe GR, Burch JD, Miller AB, et al. Tobacco use, occupation, coffee, various nutrients, and bladder cancer. J Natl Cancer Inst 1980;64:701-13.

29. Bethwaite PB, Pearce N, Fraser J. Cancer risks in painters: study based on the New Zealand Cancer Registry. Br J Ind Med 1990;47:742-6.

30. Claude JC, Frentzel-Beyme RR, Kunze E. Occupation and risk of cancer of the lower urinary tract among men. A case-control study. Int J Cancer 1988;41:371-9.

31. Schifflers $\mathbf{E}$, Jamart J, Renard V. Tobacco and occupation as risk factors in bladder cancer: a case-control study in southern Belgium. Int J Cancer 1987;39:287-92.

32. Morrison AS, Ahlbom A, Verhoek WG, et al. Occupation and bladder cancer in Boston, USA, Manchester, UK, and Nagoya, Japan. J Epidemiol Community Health 1985;39:294-300

33. Coggon D, Pannett B, Osmond C, et al. A survey of cancer and occupation in young and middle aged men. I. Cancers of the respiratory tract. Br J Ind Med 1986;332-8.

34. Williams RR, Stegens NL, Goldsmith JR. Associations of cancer site and type with occupation and industry from the Third National Cancer Survey Interview. J Natl Cancer Inst 1977;59:1147-85

35. Silverman DT, Hoover RN, Albert S, et al. Occupation and cancer of the lower urinary tract in Detroit. J Natl Cancer Inst 1983;70:237-45.

36. Colt JS, Baris D, Stewart P, et al. Occupation and bladder cancer risk in a population-based case-control study in New Hampshire. Cancer Causes Control 2004:15:759-69.

37. Gaertner RR, Trpeski L, Johnson KC. A case-control study of occupational risk factors for bladder cancer in Canada. Cancer Causes Control 2004;15:1007-19.

38. Iscovich J, Castelletto R, Esteve J, et al. Tobacco smoking, occupational exposure and bladder cancer in Argentina. Int $J$ Cancer 1987;40:734-40.

39. Cordier S, Clavel J, Limasset JC, et al. Occupational risks of bladder cancer in France: a multicentre case-control study. Int J Epidemiol 1993;22:403-11.

40. Vineis $\mathbf{P}$, Magnani C. Occupation and bladder cancer in males: a case-control study. Int J Cancer 1985;35:599-606.

41. La Vecchia C, Negri E, D'Avanzo B, et al. Occupation and the risk of bladder cancer. Int J Epidemiol 1990;19:264-8

42. Barbone F, Franceschi S, Talamini R, et al. Occupation and bladder cancer in Pordenone (north-east Italy): a case-control study. Int J Epidemiol 1994;23:58-65.

43. Golka K, Bandel T, Reckwitz T, et al. [Occupational risk factors for bladder carcinoma. A case control study]. Urologe A 1999;38:358-63.

44. Golka K, Heitmann P, Gieseler F, et al. Elevated bladder cancer risk due to colorants-a statewide case-control study in North Rhine-Westphalia, Germany. J Toxicol Environ Health A 2008;71:851-5.

45. Pelucchi C, La Vecchia C, Negri E, et al. Smoking and other risk factors for bladder cancer in women. Prev Med 2002:35:114-20.

46. Kogevinas $\mathbf{M}$, 't MA, Cordier $\mathrm{S}$, et al. Occupation and bladder cancer among men in Western Europe. Cancer Causes Control 2003;14:907-14.

47. Reulen RC, Kellen E, Buntinx F, et al. Bladder cancer and occupation: a report from the Belgian case-control study on bladder cancer risk. Am J Ind Med 2007:50:449-54.

48. Cole $\mathbf{P}$, Hoover R, Friedell GH. Occupation and cancer of the lower urinary tract. Cancer 1972;29:1250-60.

49. Decouflé $\mathbf{P}$, Stanislawczyk K, Houten L, et al. A Retrospective Survey of Cancer in Relation to Occupation. Decouflé P, Stanislawczyk K, Houten L, Bross IDJ, Viadana E, eds. Cincinnati, OH: DHEW (NIOSH) Publication No. 77-178; 1977.

50. Houten L, Bross IDJ, Viadana E, et al. Occupational cancer in men exposed to metals. Adv Exp Med Biol 1977;93-102.

51. Schoenberg JB, Stemhagen A, Mogielnicki AP, et al. Case-control study of bladder cancer in New Jersey. I. Occupational exposures in white males. J Natl Cancer Inst 1984; 72:973-81

52. Miller BA, Silverman DT, Hoover RN, et al. Cancer risk among artistic painters Am J Ind Med 1986;9:281-7.

53. Silverman DT, Levin LI, Hoover RN. Occupational risks of bladder cancer in the United States: II Nonwhite men. J Natl Cancer Inst 1989;81:1480-3.

54. Silverman DT, Levin LI, Hoover RN, et al. Occupational risks of bladder cancer in the United States: I. White men. J Natl Cancer Inst 1989;81:1472-80.

55. Burns PB, Swanson GM. Risk of urinary bladder cancer among blacks and whites: the role of cigarette use and occupation. Cancer Causes Control 1991:2:371-9
56. Zheng T, Cantor KP, Zhang $\mathrm{Y}$, et al. Occupation and bladder cancer: a population-based, case-control study in lowa. J Occup Environ Med 2002:44:685-91.

57. Risch HA, Burch JD, Miller AB, et al. Occupational factors and the incidence of cancer of the bladder in Canada. Br J Ind Med 1988;45:361-7.

58. Siemiatycki J. Risk Factors for Cancer in the Workplace. Siemiatycki J, ed. Boca Raton, Florida: CRC Press, 1991.

59. Ramanakumar AV, Nadon L, Siemiatycki J. Exposures in painting related occupations and risk of selected cancers: results from a case-control study in Montreal. Am J Ind Med 2008;51:419-27.

60. Teschke K, Morgan MS, Checkoway $\mathrm{H}$, et al. Surveillance of nasal and bladder cancer to locate sources of exposure to occupational carcinogens. Occup Environ Med 1997; 54:443-51.

61. Band PR, Le ND, MacArthur AC, et al. Identification of occupational cancer risks in British Columbia: a population-based case-control study of 1129 cases of bladder cancer. J Occup Environ Med 2005;47:854-8.

62. Dryson $\mathbf{E}$, 't MA, Walls $\mathrm{C}$, et al. Case-control study of high risk occupations for bladder cancer in New Zealand. Int J Cancer 2008;122:1340-6.

63. Pesch B, Haerting J, Ranft U, et al. Occupational risk factors for urothelial carcinoma: agent-specific results from a case-control study in Germany. MURC Study Group. Multicenter Urothelial and Renal Cancer. Int J Epidemiol 2000;29:238-47.

64. Porru S, Aulenti V, Donato F, et al. Bladder cancer and occupation: a case-contro study in northern Italy. Occup Environ Med 1996;53:6-10.

65. Gonzalez CA, Lopez-Abente G, Errezola M, et al. Occupation and bladder cancer in Spain: a multi-centre case-control study. Int J Epidemiol 1989:18:569-77.

66. Jensen $\mathbf{O M}$, Wahrendorf J, Knudsen JB, et al. The Copenhagen case-referent study on bladder cancer. Risks among drivers, painters and certain other occupations. Scand J Work Environ Health 1987;13:129-34.

67. Kunze E, Chang-Claude J, Frentzel-Beyme R. Life style and occupational risk factors for bladder cancer in Germany. A case-control study. Cancer 1992;69:1776-90.

68. Carstensen JM, Pershagen G, Eklund G. Smoking-adjusted incidence of lung cancer among Swedish men in different occupations. Int J Epidemiol 1988; 17:753-8.

69. Taeger D, Sun Y, Keil U, et al. A stand-alone windows applications for computing exact person-years, standardized mortality ratios and confidence intervals in epidemiological studies. Epidemiology 2000;11:607-8.

70. Rothman KJ. Modern Epidemiology. In: Rothman KJ, Greenland S, Lash TL, eds. 3rd ed. Philadelphia, PA, USA: Lippincott, Williams \& Wilkins, 2008:1-758.

71. Sutton AJ, Abrams KR, Jones DR, et al. Methods for Meta-Analysis in Medical Research. Sutton AJ, Abrams KR, Jones DR, Sheldon TA, Song F, eds. New York: Wiley; 2000.

72. Higgins JP, Thompson SG. Quantifying heterogeneity in a meta-analysis. Stat Med 2002:21:1539-58.

73. Huedo-Medina TB, Sanchez-Meca J, Marin-Martinez F, et al. Assessing heterogeneity in meta-analysis: 0 statistic or 12 index? Psychol Methods 2006;11:193-206.

74. DerSimonian R, Laird N. Meta-analysis in clinical trials. Control Clin Trials 1986:7:177-88.

75. Forest plots: trying to see Lewis $S$, Clarke M. The wood and the trees. BMJ 2001;322:1479-80.

76. Deeks JJ, Altman DG, Bradburn MJ. Statistical methods for examining heterogenity and combining results from several studies in meta-analysis. Systematic reviews in health care meta-analysis context. London, UK: BMJ Books, 2005:285-312.

77. Bradburn MJ. Updated and new commands for meta-analysis in Stata, 2009. http://www medepi net/meta/software/Bradburn_metan_updates pdf laccessed 24 Aug 2009).

78. Hrubec A, Blair A, Vaught J. Mortality risks by occupation among U.S. veterans of known smoking status. In: Hrubec A, Blair A, Vaught J, eds. Washington, DC, USA National Cancer Institute, 1992. NIH Publication No 92-3407.

79. Siemiatycki J, Dewar R, Nadon L, et al. Occupational risk factors for bladde cancer: results from a case-control study in Montreal, Quebec, Canada. Am J Epidemiol 1994;140:1061-80.

80. Dubrow R, Wegman DH. Cancer and Occupation in Massachussetts: a death certificate study. Am J Ind Med 1984:207-30. 